a very large anaesthetic hammer for a relatively small surgical nut. As pointed out in our Table, the length of time from the start of abdominal insufflation to deflation is less than 10 minutes on average. I understand that in some centres the operation takes rather longer and different problems then arise for the anaesthetist.

Laparoscopy we consider to be different from any other minor operation only in so far as it requires some abdominal relaxation (to allow an adequate amount of gas to be introduced into the abdomen before the trocar and cannula are inserted) and quiet respiration. The latter is of some importance as excessive movement of the intestines with respiration (which can also occur if controlled respiration is too violent) can be dangerous during the tubal diathermy. (I know of one case in which the bowe was burnt in this way). The main advantage of nitrous oxide over carbon dioxide is the elimination of excessive respiratory drive.

There should be no morbidity associated with anaesthesia for the procedure. Vomiting, as we said. is no commoner than with other minor gynaecological operations. The cardiac arrhythmias seen are innocuous, but can largely be eliminated again by using nitrous oxide for insufflation. The use of small doses of gallamine has very little effect on respiratory performance as judged by $\mathrm{PaCO}_{2}$ levels with and without the drug. Like $\mathrm{Dr}$. T. Sayer (26 February, p. 566) we do not use halothane if termination of pregnancy is also being carried out.

Dr. Nanette Gordon and colleagues (4 March, p. 625) quote a case from the literature in whom the $\mathrm{PaO}_{2}$ during laparoscopy was $46 \mathrm{~mm} \mathrm{Hg}$, but do not mention that the same patient had a $\mathrm{PaO}_{2}$ of only $50 \mathrm{~mm}$ $\mathrm{Hg}$ before pneumoperitoneum.

I can reassure Mr. P. C. Steptoe and Dr. F. N. Campbell (4 March, p. 625) that we do use a pressure-limiting device, having been convinced by him personally of its necessity before introducing the operation into our practice. The intra-abdominal pressure (properly measured) seldom exceeds $15-20 \mathrm{~cm}$ of water.

After the very large number of cases performed in this hospital, I am still unable to understand Dr. J. E. Utting's description of our method as "entirely inappropriate" (26 February, p. 566). Have your correspondents ever considered the side effects of their methods? While I am sure that they are minimal in their hands, we have found that heavy premedication can cause delayed recovery and, if opiates are used, a high incidence of nausea and vomiting postoperatively; muscular relaxation with suxamethonium causes muscle pains (often severe in these early ambulent cases); and intubation causes sore throats. Modern anaesthesia has contributed many advantages but nothing in life is free.-I am, etc.,

D. B. Scott

Department of Anaesthetics. Royal Infirmary,

\section{Mode of Action of Verapamil in Man}

SIR,-We read with interest the report of Dr. L. Schamroth and others (11 March, p. 660) which confirmed our observation made in 1969 and recently reported (9 October 1971, p. 113) that verapamil is a drug of promise in the treatment in man of dysrhythmias arising in the specialized conducting tissue of the heart. However, in the treatment of atrial fibrillation the mechanism of the regularizing effect of verapamil is not as uncertain as Dr. Schamroth and his colleagues suggest. Conduction along the atrioventricular specialized conducting tissue is under vagal control and augmentation of this activity will prolong the refractory period. The phenomenon of delay in conduction along the atrioventricular specialized conducting tissue was first demonstrated by Trendelenberg, ${ }^{1}$ and can present a problem when fast atrial pacing is used to achieve high heart rates with $1: 1$ specialized conducting tissue conduction. We have observed (unpublished) that intravenous atropine $(0.6-1.2 \mathrm{mg})$ can overcome this Trendelenberg effect. In addition, we have noted that the effect of verapamil on slowing the ventricular rate in patients with atrial fibrillation can be reversed by atropine. We would therefore repeat our suggestion that an important action of verapamil is to augment the effects of vagal tone on the specialized conducting tissue of the heart.We are, etc.,

King's College Hospital,

Brian Livesley

Trendelenberg, $\underset{\text { Ph siologie, }}{\mathbb{W}}$, Archiv für Anatomie und
271.

\section{Trimethoprim Resistance determined by} $R$ Factors

SIR,-In our paper "Trimethoprim Resistance Determined by R Factors" (Mr. M. P. Fleming and others, 18 March, p. 726) I failed to make it clear that the routine bacteriology in the U.C.H. Group is undertaken in two separate laboratories. The methods used for antibiotic sensitivity testing in the two laboratories are similar, but the patients from whom specimens derive are not. Thus my department handles, for instance, material from a large geriatric department and from general practice, while the other laboratory does not. As a result, the patterns of antibiotic resistances observed are not always alike. For instance, in my laboratory one third of urinary Klebsiella strains are found to be resistant to trimethoprim whereas in Dr. E. Joan Stokes's department the figure is lower ( 3 out of 41 strains in the last 3 months).

I apologize for any misunderstanding which might have arisen over this.-I am, etc.,

University College Hospital,

R. N. GRÜNEBERG St. Pancras Hospital,
London N.W.1

\section{"Asthma and a Lump in the Breast"}

SIr.-In the article "Second Ovinion, Please: Asthma and a Lump in the Breast" (11 March, p. 681) it was assumed that the asthma was precipitated by the psyche. It wa by no means established that the asthma was not due to allergy to the budgerigar. In favour of such a diagnosis would be the period of exposure to the budgerigar; that for what it is worth, skin testing showed sensitivity only to feathers; and that the bird was looked after in the house of a friend while she had her mastectomy and may well not have been returned to the house when seen by the health visitor.
The asthma cannot be blamed on the psyche until it has been established that the return of the bird does not precipitate an attack.-I am, etc.

Leeds, Yorks

G. W. LEWIS

SIR,-It is disappointing to read an article (11 March, p. 681) such as this and find that no assessment is made of respiratory function. The patient had haemoglobin, E.S.R., and urine examination; Bencard skin test, $x$-ray, and E.C.G., and it was suggested that she be treated with steroids. At no time was even as simple a respiratory measurement as the peak expiratory flow rate made, although this is possibly the mo-t relevant investigation. In the absence of this information it is very difficult to assess the success of the response to her plea for "someone to look at her body".-I am, etc.,

\section{Central Mi 'dlesex Hospital,}

Martin W. McNicol

\section{Births and Deaths}

SIR,--Your note on the number of births and deaths in England and Wales in 1970 and 1971 (18 March, p. 758) includes a most misleading sentence, "The net result was an increase of 6,000 in the population from these changes". This should have read, "The net result was an increase of 6,000 in the population growth from these changes." In fact the excess of births over deaths in 1970 was 209,292 , and in 1971215,681 , which produces a net increase in the population of 424,973 over the two years.

At a time when the growth of population is causing concern, it is important that the facts should be made completely clear.I am, etc.

Didsbury,

Clifford R. KaY

\section{Record Folder for General Practice}

SIR,-Dr. Gillian Strube (19 February, p. 513) discusses the advantages of the proposed use of the A4 sized folder in general practice. I was recently awarded an Upjohn travelling fellowship by the Royal College of General Practitioners to study records in general practice. Briefly, I had 800 A5 size doublepocket wallets made and these were tried by a large number of general practitioners. My conclusions were that a new form of record system in general practice was essential. The old medical record envelope has had good service for over half a century, and general practitioners are well aware of the inadequacies of this record, which is of no accepted paper size.

The new international paper size has been introduced into Britain and is here to stay. Hardly any general practitioners I have met have any idea what this new paper size revolution really means. It is a most logical system and has already been accepted by industry and most hospitals. The A4 size is slightly larger than the traditional foolscap sheet of paper. The A5 size is exactly half this size.

Most doctors are agreed that some change in the medical record system of general practice is inevitable. Our problem is which size should be adopted, the A4 or the A5. 
My A5 double-pocket wallet opens like a book with two inside gussetted pockets, which are able to take the usual hospital letter unfolded. The only item requiring folding is the large A4 hospital report. There are a number of minor advantages with this system.

The Department of Health and Social Security and the General Medical Services Committee have already given their opinions on the new A4 record size folder for general practice. About $90 \%$ of medical records in general practice do not require the large A4 hospital size of record. The A5 folder would be immensely less expensive and more convenient in the office and cheaper to produce and reduce conversion costs in practice.

Dr. Gillian Strube's second point was the change to a numerical system of filing. This has been tried in a few practices and although I have not been persuaded of its value, it is a system any general practitioner can use without inconveniencing any others.

I do not agree that the A4 folders need take up no more floor space than the old medical record envelopes. The A4 folders are large, bulky, and take up more than twice as much room.

I agree that the computer storage of records for general practice is a long way off and may never occur in ordinary general practice. I also have many personal doubts as to whether this system is in the interests of the patient, particularly when confidential information is being recorded.-I am, etc.,

Worcester

\section{A. J. Laidlaw}

SIR,-Before 20,000 general practitioners find themselves persuaded by the enthusiasts such as Dr. J. K. Hawkey and others (11 December 1971, p. 667) and Dr. Gillian Strube (19 February, p. 513) and by the administrators that a larger (A4) size of record folder is desirable they should consider some of the defects of larger folders apart from the obvious one of sheer bulk. Worst of all defects is that they allow or actually encourage the accumulation of rubbish which is already too comm $r n$ in collections of medical notes both in hospital and outside.

I have recently started to collect gems from general practice notes, such as that dated 1949 saying "I would be grateful for a reply to my letter of three months ago" and still filed 22 years later (did he ever get a reply?); such gems abound. Then there is the series of letters which read "Mr. A has a hernia: I will repair it": "I have just repaired Mr. A's hernia"; "Mr. A has left hospital after his hernia repair"; and "Mr. A has recovered from his hernia"-only one of which need usually be kept. Then again, there is the string of letters which say that $\mathrm{Mr}$. B is making satisfactory progress and will be seen again soon, each of which supersedes its predecessor. Larger folders mean less incentive to consign these superfluous letters to the waste paper basket.

Another disadvantage of bigger folders is that they encourage the use of backing sheets as permanent mounts for laboratory reports of ephemeral value. I have recently received a set of notes from a doctor who is a distinguished exponent of the virtues of larger folders. I increased the value of the notes in reducing them to a third of their previous bulk by removing a large, tough backing sheet and most of its adherent haemoglobin reports which had been collected during a pregnancy which ended a year ago. The reports had been valuable then but were now too numerous to be studied afresh each time; just two, unmounted, were sufficient to show later doctors the general trend. Devices like backing sheets are impressive at the time but we must remember that any plan we follow must allow for 50 years or more of the accumulation of information.

I suggest, Sir, that if any patient's old general practice (or hospital?) notes have become too numerous or too bulky to fit into the present $5 \times 7 \frac{1}{2}$ inch $(12 \times 18 \mathrm{~cm})$ record envelope they are too numerous to be read except on very rare occasions, and will take so much time to digest that they will detract from the care of other patients. They may as well be put, complete, untouched, into the dustbin (also, presumably, size A4).-I am, etc.,

Southampton

John L. STRUthers

\section{Confusion of Ampoules}

SIR,-A recent report in the national press (Daily Express, $8 \mathrm{March}$ ) of an ampoule of morphine being found alongside a vial of penicillin in general practice instead of distilled water prompts me to draw attention to a practice that I have carried out for years. When prescribing penicillin preparations for injection I always specify the water in $5 \mathrm{ml}$ ampoules. The basic price is only a fraction of a penny more than the $2 \mathrm{ml}$, but it ensures that there can be no confusion with any other $2 \mathrm{ml}$ ampoules which during its life in a visiting bag may lose its markings. - I am, etc.,

London N.W.10

Denys E. Howells

\section{Discontinuation of Evening Surgery}

SIR,-My practice decided to dispense with evening surgeries for all time two years ago. The decision gave cause for considerable but yet not unsurmountable resentment. This major reform of our practice routine would have enjoyed a much less grudging acceptance than it did had it not been considered by the local press as a dastardly retrograde step.

Press hostilities culminated in criticism of myself and colleagues in the national daily newspapers. Ironicallv, the net results of these reports has been that other doctors have become intrigued and they have inquired as to how we effected our changes and the nature of the difficulties we encountered.

My partners and I hope that our experiences will encourage many more general practitioners to reappraise their practice arrangements. We are the first to recognize that the changes we have implemented cannot be adopted universally, and we do not necessarily advocate universal application. Many general practitioners have hospital and other appointments outside general practice and their practice routine is arranged accordingly. However, we are convinced that there are also many general practitioners who have evening surgeries more through force of habit and the fear of untrodden paths than for patient needs.

Our reorganized day has brought us immeasurable benefits. We have now a regular eight-hour day (9 a.m.-5 p.m.), which, incidentally, is also a sound business proposition, and we have filled the gaps between morning and afternoon surgeries with home visiting and a variety of new clinic sessions. We are much happier in our work and more efficient. Our families have suddenly become aware of our physical existence and we can to some extent participate in regular pastimes. It has been our experience that the health of our patients has not been adversely affected by the absence of evening surgeries.

All this has been achieved without detriment to our 24-hour responsibility.-I am, etc.

Partington

T. TERNENT Manchester

\section{Radiological Equipment}

SIR,-As a radiologist in a busy hospital, I am becoming increasingly exasperated with the unreliability and over-sophistication of the modern $x$-ray apparatus which we are forced to buy. We are in the hands of the manufacturers who, year by year, add to the complication of their machinery.

Soon after installation of our very expensive new apparatus we began to suffer failure of the gadgetry which revealed multiple defects in design and manufacture. We also discovered deficiencies in service facilities and unavailability of replacement parts, whch can be the most damaging feature of all. At a time when the demand for $x$-ray examinations is rising at $10 \%$ per annum, we are constantly in danger of being unable to fulfil our commitments owing to endless equipment failure.

The manufacturers have provided us with some excellent equipment in the past which has enabled us to cope with an everincreasing work-load, but now they seem to be more concerned with promoting unreliable electronic trickery than with providing soundly designed and robust apparatus with a long working life.

It is high time that the Department of Health established a radiological laboratory to test all the new apparatus before it is purchased for the National Health Service, and equipment thus tested should be given an appropriate certificate.-I am, etc.,

Ipswich, Suffolk

J. W. MILLS

\section{“Academic" G.P.s}

SIR,-It is debated whether general practice can constitute an academic discipline. ${ }^{1}$ Dr. W. Anthony Ball evades the debate (19 February, p. 513) while denigrating the lecturer in general practice because he is "an academic." However, Professor A. P. M. Forrest has recently defined the academic as one who works in a university department. ${ }^{2}$ To be an academic is therefore a concomitant of, and not a prerequisite for, a university appointment.

In any general practice the three elements of service, teaching, and research are not mutually exclusive. This is reflected in the work of academic departments of general 